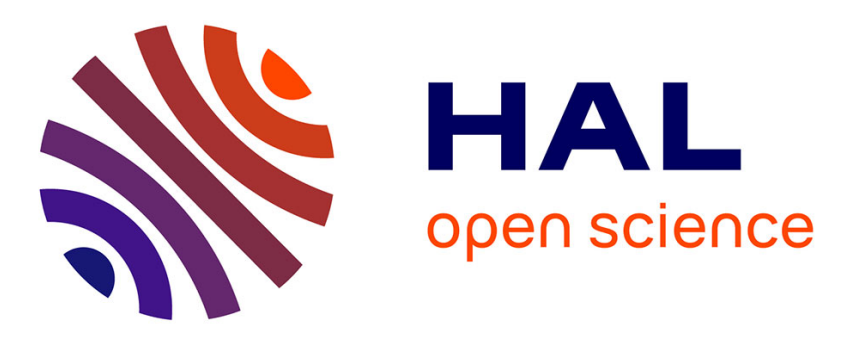

\title{
A sliding mode control design for aircraft rendezvous at meter fix
}

Thierry Miquel, Felix Mora-Camino, Karim Achaibou

\section{To cite this version:}

Thierry Miquel, Felix Mora-Camino, Karim Achaibou. A sliding mode control design for aircraft rendezvous at meter fix. AIAA GNC 2005, AIAA Guidance, Navigation and Control Conference and Exhibit, Aug 2005, San Francisco, United States. pp xxxx, 10.2514/6.2005-6279 . hal-00998737

\section{HAL Id: hal-00998737 \\ https://hal-enac.archives-ouvertes.fr/hal-00998737}

Submitted on 2 Jun 2014

HAL is a multi-disciplinary open access archive for the deposit and dissemination of scientific research documents, whether they are published or not. The documents may come from teaching and research institutions in France or abroad, or from public or private research centers.
L'archive ouverte pluridisciplinaire HAL, est destinée au dépôt et à la diffusion de documents scientifiques de niveau recherche, publiés ou non, émanant des établissements d'enseignement et de recherche français ou étrangers, des laboratoires publics ou privés. 


\title{
A sliding mode control design for aircraft rendezvous at meter fix
}

\author{
Thierry Miquel* \\ Centre d'Etudes de la Navigation Aérienne, Toulouse, FRANCE \\ Félix Mora-Camino ${ }^{\dagger}$ \\ Ecole Nationale de l'Aviation Civile and LAAS du CNRS, Toulouse, FRANCE \\ and \\ Abdelkrim Achaibou ${ }^{*}$ \\ LAAS du CNRS, Toulouse, FRANCE
}

\begin{abstract}
The delegation to the flight crew of some tasks currently performed by air traffic controllers provides new perspectives to potentially increase air traffic control efficiency. More specifically, the task of establishing properly spaced landing sequences is very demanding in heavy traffic conditions for the air traffic controllers in charge of the terminal maneuvering area. Automatic merging and station keeping operations could relieve air traffic controller of providing time consuming radar vectoring instructions. The objective of this communication is to provide technical insight into the airborne devices and algorithms which may be used onboard aircraft to automatically achieve a specified distance or delay with respect to another aircraft at a specified meter fix. A nonlinear control law based on sliding mode control is proposed to control the lateral motion of the trailing aircraft. The design is followed by two illustrative examples which show the effectiveness of the proposed approach.
\end{abstract}

\section{Introduction}

$\mathrm{T}$

HE main task of air traffic controllers managing terminal traffic is to sequence, merge and space aircraft for landing. An example of typical flight path for arriving aircraft at an airport is depicted in Figure 1.

When aircraft cross the meter fixes, the following aircraft must be spaced at a prescribed minimum distance behind. Indeed, aircraft shall always be protected at least from wake turbulence generated by others aircraft. The minimum wake turbulence separation adopted by the civil aviation authorities depends upon the maximum takeoff weights of the aircraft involved ${ }^{1}$.

The task of establishing properly spaced landing sequences is very demanding in heavy traffic conditions ${ }^{2}$. As a consequence, an automation tool named Arrival Manager $(A M A N)$ often helps air traffic controllers to build a sequence of aircraft in order to safely and expeditiously land them ${ }^{3}$.

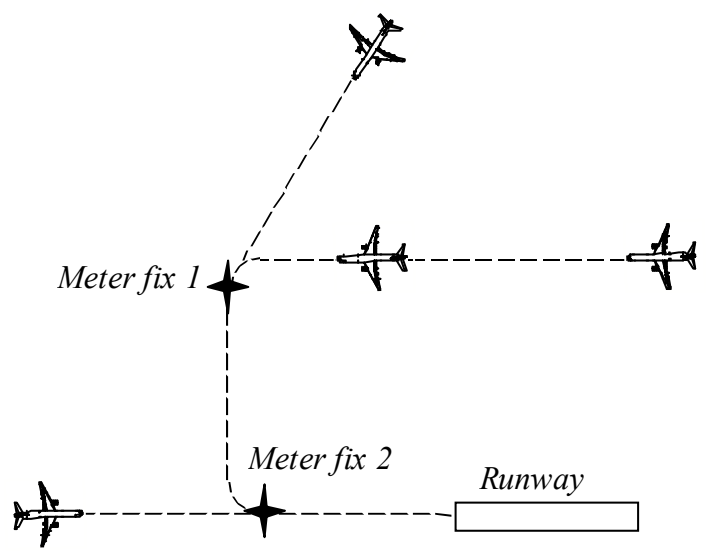

Figure 1: Example of sequencing and merging operations

\footnotetext{
* Research engineer, PhD, Airborne Surveillance, Collision Avoidance and Separation Department, miquel@cena.fr

${ }^{\dagger}$ Senior Researcher at LAAS du CNRS, Professor of Automatic Control and Avionics at Ecole Nationale de l'Aviation civile, Felix.MORA@enac.fr

*Senior Researcher at LAAS du CNRS, achaibou@laas.fr

Copyright $\odot 2005$ by DSNA/DTI/SDER. Published by the American Institute of Aeronautics and Astronautics, Inc., with permission.
} 
Unfortunately, the airborne counterpart of the arrival manager which could help the flight crew to merge its aircraft towards a meter fix according to a sequence constraint is not yet available. Indeed, despite the fact that current aircraft's Flight Management System (FMS) have the ability to navigate over predefined paths, they are not capable to meet delay over meter fixes relatively to another aircraft. As far as such a new capability onboard aircraft needs some surveillance capabilities, and more specifically the knowledge of the leading aircraft position and velocity, the Automatic Dependent Surveillance-Broadcast $(A D S-B)$ is a potential key enabler to support this surveillance requirement ${ }^{4}$.

Aircraft equipped with $A D S-B$ capabilities broadcast their position, velocity and identification periodically (e.g. every second). Any neighboring aircraft capable of receiving those data will therefore be capable to track surrounding traffic.

Automatic merging and station keeping operations could relieve air traffic controller of providing time consuming radar vectoring instructions to the trailing aircraft once the flight crew has accepted the relative guidance clearance. Thus, the expected benefit of such new capabilities onboard aircraft is an increase of air traffic controller availability, which could result in increased air traffic efficiency and / or capacity ${ }^{5}$. Enhancement of flight crew airborne traffic situational awareness with associated safety benefits is also expected.

Preliminaries studies have mainly investigated the station keeping phase without taking into consideration the merging phase. This field is addressed for $U A V \mathrm{~S}$ or military aircraft by means of linear and nonlinear techniques for example by ${ }^{6}$ and ${ }^{7}$. However, research for civil aircraft where safety and passenger comfort are crucial issues is still in its initial stage. Indeed, ${ }^{8}$ focuses on station keeping performed manually, whereas ${ }^{4}$ develops a proportional, integral and derivative $(P I D)$ law to control longitudinal station keeping

However, operations where the merging constraint is relaxed at the meter fix are also possible, and may yield in more efficient operations. The purpose of this paper is to investigate the design of a new autopilot mode dedicated to the achievement of a specified delay / distance between aircraft at a specified meter fix.

The paper is organized as follows: in the preliminaries, reference frame, aircraft model and spacing objectives are introduced. This leads to the nonlinear state space representation which is used in this paper. The subsequent section presents the design of the sliding mode controller to control the lateral motion of the trailing aircraft. Two illustrative examples are then presented in order to show the effectiveness of the proposed approach. Finally, conclusions are raised.

\section{Preliminaries}

\section{A. Aircraft model}

In the following, a fully coordinated aircraft (i.e. side-slip angle is assumed to be zero) flying over a flat and non rotating earth is assumed. In addition, standard atmosphere with no wind is considered.

As in many modern jets, it is also assumed that the trailing aircraft is at least equipped with two autopilots which operate in a decoupled manner:

- The speed of the aircraft is controlled thanks to an airspeed hold autopilot. Following ${ }^{6}$, the airspeed autopilot is modeled in this paper as a first order model, where $V_{c}$ is the commanded airspeed, $V$ the actual speed and $\tau_{V}$ a time constant.

$$
\dot{V}=\frac{V_{c}-V}{\tau_{V}}
$$

- The bank angle $\varphi$ is controlled thanks to an holding function of the lateral autopilot ; for small bank angle and loading factors, the following relationship between heading rate and bank angle is assumed, where $g$ is the acceleration of gravitation, $\varphi_{c}$ the commanded bank angle and $V$ the actual airspeed:

$$
\dot{\psi}=\frac{g \cdot \varphi_{c}}{V}
$$

A more realistic model for the heading dynamic would have been obtained by considering that the bank angle is driven by a first order model of the following form, where $\varphi$ is the actual bank angle and $\tau_{\varphi}$ a time constant:

$$
\dot{\varphi}=\frac{\varphi_{c}-\varphi}{\tau_{\varphi}}
$$

For civil aircraft, the time constant $\tau_{\varphi}$ is small compared to the time constant $\tau_{V}$. As a consequence, the bank angle is viewed in this paper as the fast dynamics, and the time constant $\tau_{\varphi}$ is removed for the purpose of designing the control law. Nevertheless, it has been taken into account within the simulations performed to illustrate the approach. 
So, the acceleration $a$ and the bank angle $\varphi$ will be considered as inputs during the design process:

$$
\left\{\begin{array}{l}
\dot{V}=a \\
V \dot{\psi} \approx g \varphi
\end{array}\right.
$$

\section{B. State space representation}

In this paper, the reference frame which is used is affixed to the trailing aircraft. From Figure 2, the following notations are adopted:

- $L$ stands for the leading aircraft, and $F$ for the trailing aircraft (follower);

- $d_{L}$ stands for the distance between the leading aircraft and the meter fix $P$, whereas $d_{F}$ stands for the distance between the trailing aircraft and the meter fix.

As far as some simulations have shown the interest to express separation objective in terms of delay rather than distance in terminal maneuvering area ${ }^{8}$, this paper considers a constant time delay $T$ as the separation objective at the meter fix.

The delay at meter fix $P$ between the leading aircraft $L$ and the trailing aircraft $F$ is defined as follows, where $V_{l}$ stands for the projection of $V_{F}$

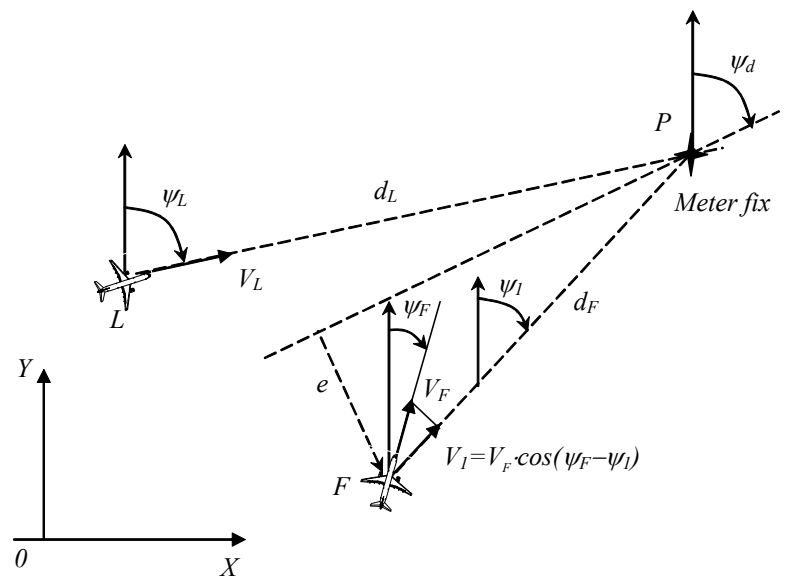

Figure 2: Reference frame and notations onto the line $F P$ :

$$
\tau=\frac{d_{F}}{V_{1}}-\frac{d_{L}}{V_{L}}
$$

Unfortunately, this definition does not imply that the leading and the trailing aircraft have the same airspeed $\left(V_{F}=V_{L}\right)$ as far as the specified delay is achieved $(\tau=T)$. Thus, the expression of the delay adopted in this paper is slightly modified as follows:

$$
\tau=\frac{d_{F}-d_{L}}{V_{L}}
$$

With this new definition, it is worth noticing that $\tau=\tau$ as far as $V_{F}=V_{L}$.

The product $\tau V_{L}$ expresses the separation between the two aircraft at the meter fix, which shall be compliant with the current civil aviation regulations standards.

Denoting by $\psi_{1}$ the orientation of the line $F P$, the time derivative of the delay $\tau$ reads:

$$
\dot{\tau}=\frac{V_{F} \cos \left(\psi_{F}-\psi_{1}\right)}{V_{L}}-1
$$

Furthermore, the time derivative of $\psi_{1}$ is given by:

$$
d_{1} \dot{\psi}_{1}=V_{F} \sin \left(\psi_{F}-\psi_{1}\right)
$$

Finally, the dynamics of the cross track error e is:

$$
\dot{e}=V_{F} \sin \left(\psi_{F}-\psi_{d}\right)
$$

\section{Controller design}

The purpose of this section is to design a feedback control law so that the predicted delay $\tau$ at meter fix $P$ moves towards the desired delay $T$ and so that the cross-track error $e$ moves towards 0 . The state vector $\underline{x}$ is defined by $\underline{x}=(\tau, e)$. So, it is desired that the equilibrium point that $\underline{x}_{e}=(T, 0)$ is globally asymptotically stable $(G A S)$. This implies that $\dot{\tau} \rightarrow 0$ and $\dot{e} \rightarrow 0$. As a consequence, $\psi_{l}$ and $\psi$ shall move towards $\psi_{d}$.

To achieve this objective, let us select two sliding surfaces as follows, where $\lambda_{1}$ and $\lambda_{2}$ are positive constants:

$$
\left\{\begin{array}{l}
s_{1}=\dot{e}+\lambda_{1} e \\
s_{2}=\dot{\tau}+\lambda_{2}(\tau-T)
\end{array}\right.
$$

As a consequence, as far as the sliding mode surfaces move towards zero the cross track error $e$ and the delay $\tau$ move towards the desired values: 


$$
\left\{\begin{array}{l}
s_{1} \rightarrow 0 \Rightarrow \dot{e}+\lambda_{1} e \rightarrow 0 \Rightarrow e \rightarrow 0 \\
s_{2} \rightarrow 0 \Rightarrow \tau+\lambda_{2}(\tau-T) \rightarrow 0 \Rightarrow \tau \rightarrow T
\end{array}\right.
$$

The time derivative of those sliding surfaces is chosen as follows, where $\lambda_{s 1}, \lambda_{s 2}, \varepsilon_{1}$, and $\varepsilon_{2}$ are positive constants:

$$
\begin{gathered}
{\left[\begin{array}{c}
\dot{s}_{1} \\
\dot{s}_{2}
\end{array}\right]=-Q\left[\begin{array}{l}
s_{1} \\
s_{2}
\end{array}\right]} \\
Q=\left[\begin{array}{cc}
\lambda_{s 1} & \varepsilon_{1} \lambda_{s 2} \\
\varepsilon_{2} \lambda_{s 1} & \lambda_{s 2}
\end{array}\right]
\end{gathered}
$$

In order to ensure that the matrix $Q$ is positive definite, $\lambda_{s l}, \lambda_{s 2}, \varepsilon_{1}$, and $\varepsilon_{2}$ shall be chosen as follows:

$$
\frac{\left|\varepsilon_{1} \lambda_{s 2}+\varepsilon_{2} \lambda_{s 1}\right|}{2 \sqrt{\lambda_{s 1} \cdot \lambda_{s 2}}}<1
$$

On the other hand, the expressions of the time derivative of the sliding surfaces are:

$$
\begin{gathered}
{\left[\begin{array}{l}
\dot{s}_{1} \\
\dot{s}_{2}
\end{array}\right]=\left[\begin{array}{c}
\ddot{e}+\lambda_{1} \dot{e} \\
\ddot{\tau}+\lambda_{2} \dot{\tau}
\end{array}\right]=\Delta(\underline{x})\left[\begin{array}{l}
a \\
\varphi
\end{array}\right]+\left[\begin{array}{c}
\sigma_{10} \\
\sigma_{20}
\end{array}\right]} \\
\Delta(\underline{x})=\left[\begin{array}{cc}
\sin \left(\psi-\psi_{d}\right) & g \cos \left(\psi-\psi_{d}\right) \\
\frac{\cos \left(\psi-\psi_{1}\right)}{V_{L}} & -\frac{g \sin \left(\psi-\psi_{1}\right)}{V_{L}}
\end{array}\right] \\
{\left[\begin{array}{l}
\sigma_{10} \\
\sigma_{20}
\end{array}\right]=\left[\begin{array}{cc}
\lambda_{1} \dot{e} \\
\frac{V \dot{\psi}_{1}}{V_{L}} \sin \left(\psi-\psi_{1}\right)+\lambda_{2} \dot{\tau}
\end{array}\right]}
\end{gathered}
$$

In the following, the term $V \dot{\psi}_{1} \sin \left(\psi-\psi_{1}\right) / V_{L}$ will be neglected in the expression of $\sigma_{20}$ to avoid the singularity at $d_{1}=0$ (cf. equation (8))

As far as the matrix $\Delta(\underline{x})$ is invertible, the control $\underline{u}=(a, \varphi)^{T}$ is given by:

$$
\begin{gathered}
{\left[\begin{array}{c}
a \\
\varphi
\end{array}\right]=\Delta^{-1}(\underline{x})\left[\begin{array}{l}
\dot{s}_{1}-\sigma_{10} \\
\dot{s}_{2}-\sigma_{20}
\end{array}\right]} \\
\Delta^{-1}(\underline{x})=\left[\begin{array}{cc}
\frac{\sin \left(\psi-\psi_{1}\right)}{\cos \left(\psi_{1}-\psi_{d}\right)} & \frac{V_{L} \cos \left(\psi-\psi_{d}\right)}{\cos \left(\psi_{1}-\psi_{d}\right)} \\
\frac{\cos \left(\psi-\psi_{1}\right)}{g \cos \left(\psi_{1}-\psi_{d}\right)} & -\frac{V_{L} \sin \left(\psi-\psi_{d}\right)}{g \cos \left(\psi_{1}-\psi_{d}\right)}
\end{array}\right]
\end{gathered}
$$

When $\psi$ and $\psi_{1}$ are close to the desired value $\psi_{d}$, and assuming $\varepsilon_{1}=\varepsilon_{2}=0$, the proposed control law reduces to a classical proportional and derivative control:

$$
\left\{\begin{array}{l}
a \approx-V_{L}\left(\lambda_{s 2} \lambda_{2}(\tau-T)+\left(\lambda_{s 2}+\lambda_{2}\right) \dot{\tau}\right) \\
\varphi \approx-\left(\lambda_{s 1} \lambda_{1} e+\left(\lambda_{s 1}+\lambda_{1}\right) \dot{e}\right) / g
\end{array}\right.
$$

\section{Illustrative examples}

\section{A. Scenarios}

In this section, two scenarios are designed in order to illustrate the properties of the control laws previously designed.

For both scenarios, the leading aircraft trajectory starts at $\mathrm{x}_{0}=0 \mathrm{NM}$ and $\mathrm{y}_{0}=0 \mathrm{NM}$, with initial airspeed of 220 $\mathrm{kts}$ and heading of 0 degrees. It is supposed to broadcast its data every second ( $A D S-B$ basic assumption).

In order to assess the robustness of the control law to airspeed variations from the leading aircraft, the leading aircraft is assumed to reduce its airspeed towards $180 \mathrm{kts}$ after 3 minutes of flight.

The meter fix point $P$ is situated at $x_{r d v}=0 \mathrm{NM}$ and $y_{r d v}=35 \mathrm{NM}$, and the desired heading is $\psi_{d}=-90$ degrees.

Two 'extreme' scenarios are assessed:

- In the first scenario, the trailing aircraft starts 'far from' the leading aircraft, and is 'late' compared to the desired delay. More specifically, its trajectory starts at $\mathrm{x}_{0}=+40 \mathrm{NM}, \mathrm{y}_{0}=30 \mathrm{NM}$, and the initial heading is -80 degrees (cf. Figure 3); 
- In the second scenario, the trailing aircraft starts 'very close' to the leading aircraft, and is 'early' compared to the desired delay. More specifically, its trajectory starts at $\mathrm{x}_{0}=+20 \mathrm{NM}, \mathrm{y}_{0}=35 \mathrm{NM}$, and the initial heading is -90 degrees (cf. Figure 7).

For both scenarios, the trailing aircraft initial airspeed is $200 \mathrm{kts}$

The requested delay for the trailing aircraft is constant and equal to $90 \mathrm{sec}$ behind the leading aircraft at the meter fix. In addition, it is requested that the trailing aircraft airspeed is the same than the leading aircraft airspeed, i.e. 180 kts.

The simulation ends as far as the distance between the leading aircraft and the meter fix point is lower than 3 NM.

During the simulations, the bank angle $\varphi$ and the airspeed (denoted $C A S$ ) of the trailing aircraft are limited to the following 'passenger comfort' values:

$$
\left\{\begin{array}{l}
-20 \mathrm{deg} . \leq \varphi \leq+20 \mathrm{deg} . \\
140 \mathrm{kts} \leq C A S \leq 250 \mathrm{kts}
\end{array}\right.
$$

In addition, longitudinal acceleration is limited to $0.05 \times \mathrm{g}$ and roll velocity to $5 \mathrm{deg}$./ $/ \mathrm{sec}$. In order to take into account the actuator dynamics, bank angle is filtered through a first order low pass filter with a time constant of 1.5 seconds, whereas speed control is filtered through a first order low pass filter with a time constant of 5 seconds.

The time constant $\tau_{V}$ of the airspeed hold autopilot and the time constant $\tau_{\varphi}$ of the bank angle hold autopilot have been set as follows:

$$
\left\{\begin{array}{l}
\tau_{V}=10 \mathrm{sec} \\
\tau_{\varphi}=1.5 \mathrm{sec}
\end{array}\right.
$$

Finally, the values of the constants defining the output vector dynamics have been chosen as follows:

$$
\left\{\begin{array} { l } 
{ \lambda _ { 1 } = 0 . 0 5 \mathrm { sec } ^ { - 1 } } \\
{ \lambda _ { s 1 } = 0 . 0 0 5 \mathrm { sec } ^ { - 1 } } \\
{ \varepsilon _ { 1 } = - 0 . 0 0 7 N M / \mathrm { sec } }
\end{array} \text { and } \left\{\begin{array}{l}
\lambda_{2}=0.1 \mathrm{sec}^{-1} \\
\lambda_{s 2}=0.01 \mathrm{sec}^{-1} \\
\varepsilon_{2}=0 \mathrm{sec} / N M
\end{array}\right.\right.
$$

\section{B. Results for scenario 1}

Figure 3 shows the movements of the leading and trailing aircraft in the horizontal plane. As expected, the two aircraft move towards the meter fix. In addition, the trailing aircraft accelerates in order to achieve the desired delay. This is highlighted in Figure 4 and Figure 5, where the evolution of the airspeed and bank angle controls is shown. It can be seen that the controls remain quite smooth.

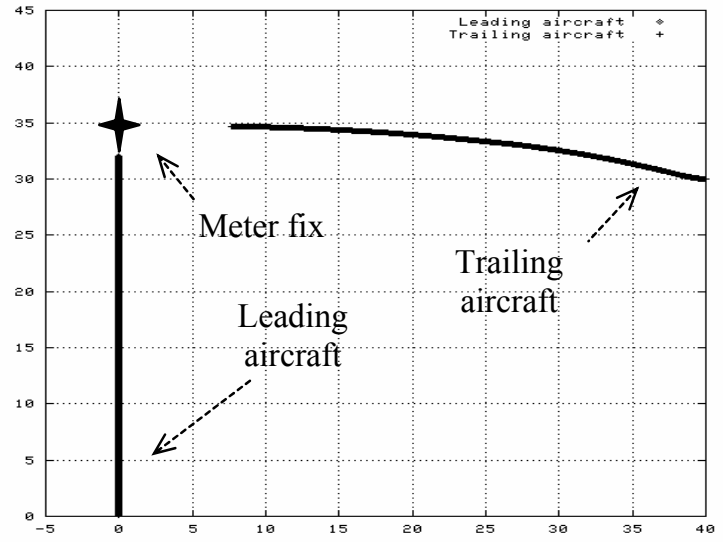

Figure 3: Leading aircraft and trailing aircraft trajectories in the horizontal plane

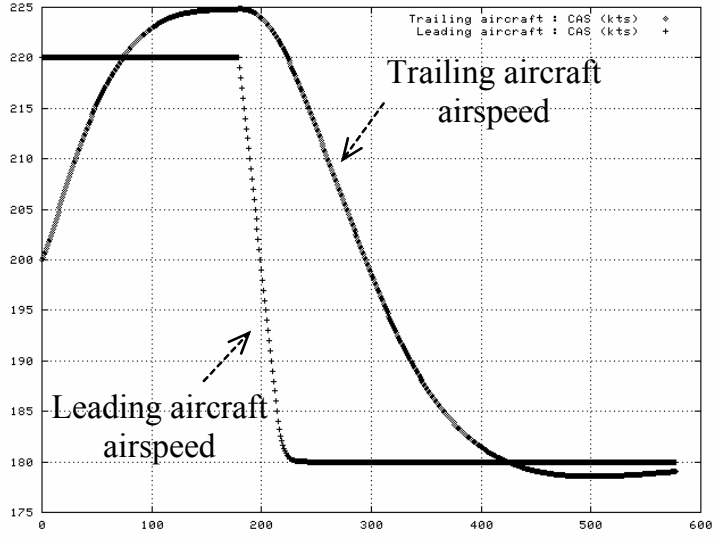

Figure 4: Leading aircraft and trailing aircraft airspeed (kts) versus time (sec)

Finally, the predicted delay $\tau$ at the meter fix between the two aircraft is showed in Figure 10. The peak is due to the deceleration of the leading aircraft. As expected, the predicted delay moves towards the desired $90 \mathrm{sec}$. 


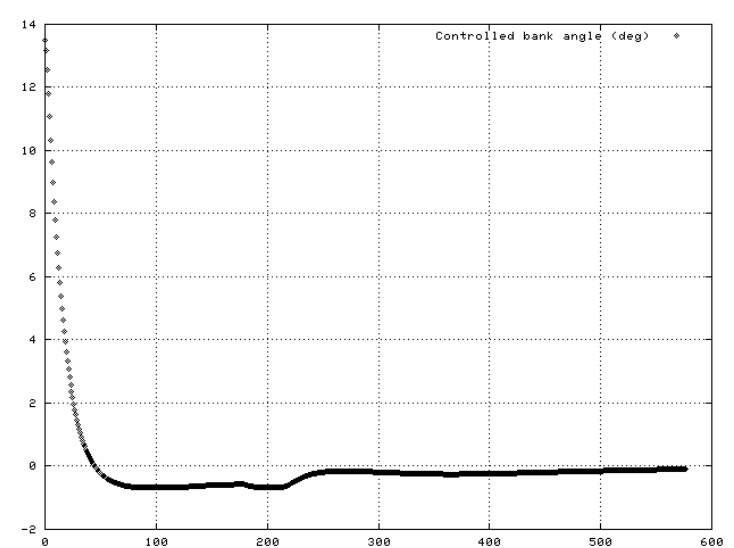

Figure 5: Bank angle control versus time (sec)

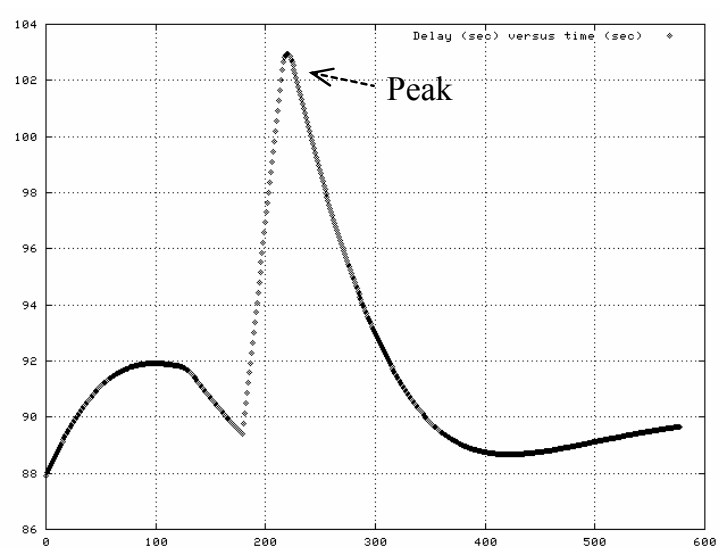

Figure 6: Predicted delay (in sec) at the meter fix between the two aircraft as a function of time (in sec)

\section{Results for scenario 2}

Figure 7 shows the movements of the leading and trailing aircraft in the horizontal plane. As expected, the two aircraft move towards the meter fix. In addition, the trailing aircraft decelerates and move away of the leading aircraft at the beginning of the scenario in order to compensate its advance. This is highlighted in Figure 8 and Figure 9, where the evolution of the airspeed and bank angle controls is shown.

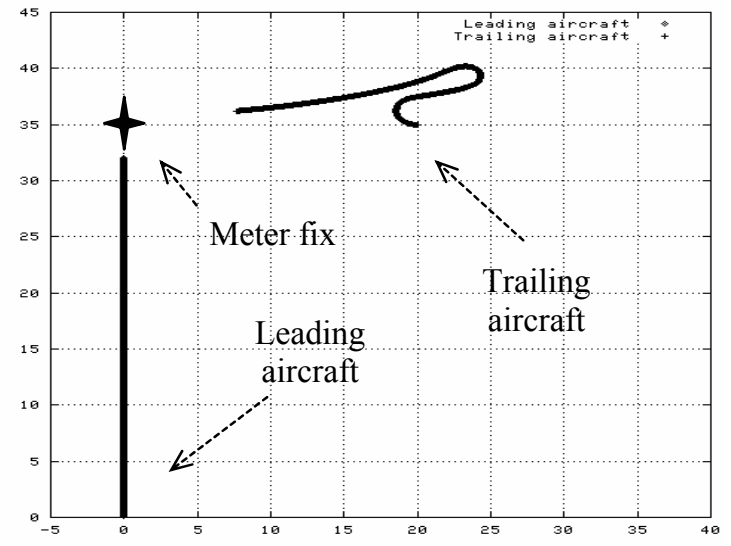

Figure 7: Leading aircraft and trailing aircraft trajectories in the horizontal plane

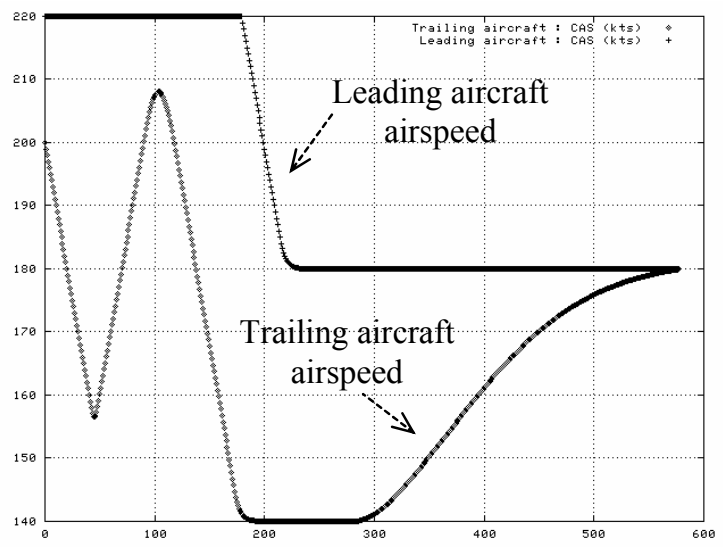

Figure 8: Leading aircraft and trailing aircraft airspeed (kts) versus time (sec)

Finally, the predicted delay $\tau$ at the meter fix between the two aircraft is showed in Figure 10. As expected, the predicted delay moves towards the desired $90 \mathrm{sec}$.

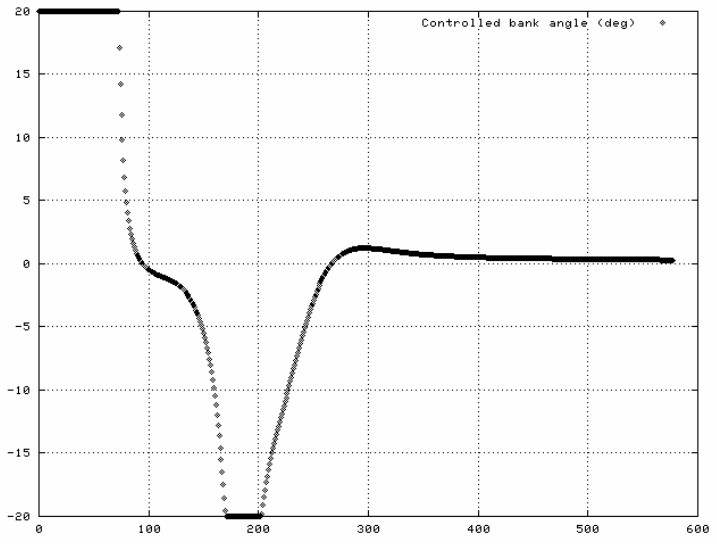

Figure 9: Bank angle control versus time (sec)

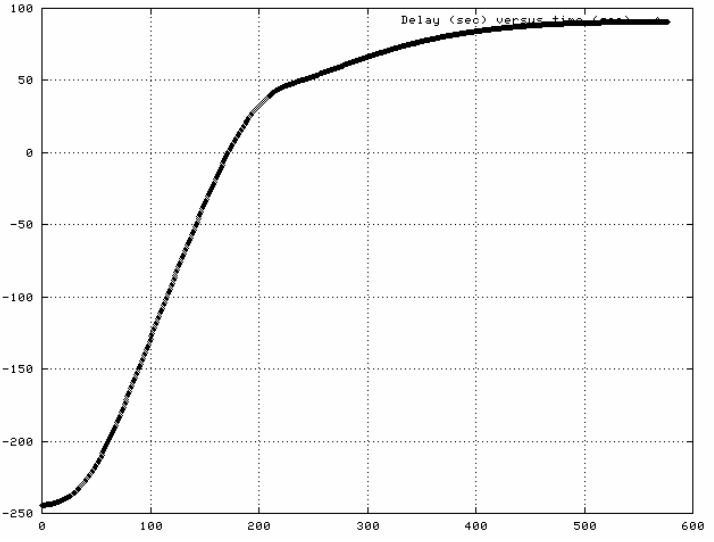

Figure 10: Predicted delay (in sec) at the meter fix between the two aircraft as a function of time (in sec) 


\section{Conclusion}

In this paper, the design of a new autopilot mode dedicated to the achievement of a specified delay / distance between commercial aircraft at a specified meter fix has been considered.

This envisioned new capability onboard commercial aircraft takes advantage of the Automatic Dependent Surveillance-Broadcast $(A D S-B)$ and provides new perspectives to potentially increase air traffic control efficiency. It could be the airborne counterpart of the ground based arrival manager.

The proposed approach is based on sliding mode control technique. It controls airspeed and lateral motion of the trailing aircraft in order to lengthen or shorten the trailing aircraft trajectory according to the initial conditions and the desired delay at the meter fix. It achieves global asymptotic stability of the desired cross track error and delay / distance at the meter fix.

Simulation results based on a typical arrival procedure illustrates the efficiency of the proposed design. Nevertheless, additional studies in terms of operational scenarios and taking into account the vertical motion of the aircraft are needed in order to refine and validate the proposed design.

\section{Acknowledgments}

The authors wish to thank Francis Casaux and Jean-Marc Loscos from the Centre d'Études de la Navigation Aérienne for their helpful inputs and comments.

\section{References}

1 International Civil Aviation Organization, Air Traffic Services - Annex 11, Montréal (2001)

2 Kayton M., Fried W., Avionics navigation systems, $2^{\text {nd }}$ edition, John Wiley \& Sons, New York, Chap. 14, pp.642-689 (1997)

3 Chabrol C., Notes sur l'outil MAESTRO à CDG, CENA/NT01-094 (2001)

4 Ivanescu D., Hoffman E., Zeghal K., Impact of ADS-B link characteristics on the performances of in-trail following aircraft, AIAA GNC Conference, Monterey, USA (2002)

5 European commission \& Eurocontrol, CARA/ASAS Activity 5 description of a first package of GS/AS applications, version 2.2 (2002)

6 Pachter M., D'Azzo JJ., Proud AW., Tight formation flight control, Journal of Guidance, Control, and Dynamics, Vol. 24, pp246-254 (2001)

7 Singh SN., Zhang R., Chandler P., Banda S., Decentralized nonlinear robust control of UAVs in close formation, International Journal of Robust and Nonlinear Control, Vol. 13 pp1057-1078 (2003)

8 Agelii M., Olausson C., Flight deck simulations of station keeping, ATM R\&D seminar, Santa Fe, paper no. 17 (2001)

9 Vinken P., Hoffman E., Zeghal K., Influence of speed and altitude profile on the dynamics of in-trail following aircraft, Proceeding of AIAA Guidance Navigation and Control Conference. Denver, USA, Paper No. 2000$4362(2000)$ 